\title{
Critical Illness Polyneuromyopathy and the Diagnostic Dilemma
}

\author{
Sulakshana Sulakshana ${ }^{1}$, Banavathu Kishansing Naik ${ }^{2}$
}

\begin{abstract}
Critical illness polyneuromyopathy is a growing concern in intensive care units, but its presentation within $24-48$ hours of admission is very unusual. Such presentations should be carefully scrutinized, especially in the presence of severe hypokalemia.

Keywords: Critical illness polyneuromyopathy, Diabetic ketoacidosis, Hypokalemia.

Indian Journal of Critical Care Medicine (2020): 10.5005/jp-journals-10071-23485
\end{abstract}

Sir,

We read with immense interest the article titled "An Unusual Case of Critical Illness Polyneuromyopathy" by Mahashabde et al. ${ }^{1}$ We appreciate that critical illness polyneuromyopathy is a growing concern in intensive care units leading to difficult weaning with prolonged hospitalizations. But there are some major concerns in this case report which we want to bring to notice:

- The patient was diagnosed with diabetic ketoacidosis (DKA) precipitated by infection. Dyselectrolytemia in the form of hyperchloremic acidosis, hypokalemia, and hypophosphatemia are known complications of DKA management. The potassium level of $1.9 \mathrm{mEq} / \mathrm{L}$ with $\mathrm{pH}$ of 6.9 at admission suggests severe potassium depletion. Hypokalemia further worsens as the acidosis gets corrected with fluid and insulin therapy due to transcellular shift. Severe hypokalemia may itself present as acute flaccid paralysis. ${ }^{2}$

- Nerve conduction studies in severe hypokalemia have shown severe reduction in amplitudes of the compound muscle action potential with rarely reduced sensory nerve action potential. ${ }^{3}$ These electrophysiological findings mimic axonal neuropathy.

- According to one study, serum CPK was elevated in $68 \%$ of cases of hypokalemic paralysis with significantly higher values in the secondary group compared to the primary hypokalemic paralysis group. ${ }^{4}$

- The authors themselves quoted that critical illness polyneuropathy may present as early as 72 hours of ICU admission, but the flaccid paralysis requiring intubation was evident on the second day of admission itself in the present case report. $^{5}$

- Whether magnesium levels were checked and corrected in case of persistent hypokalemia?

- What were the phosphate levels as diabetic ketoacidosis is often associated with hypophosphatemia leading to weaning difficulties?

- Thus the flaccid paralysis with associated laboratory and electrophysiological study findings presenting between 24 hours
1,2Department of Critical Care, Shri Ram Murti Smarak Institute of Medical Sciences, Bareilly, Uttar Pradesh, India

Corresponding Author: Banavathu Kishansing Naik, Department of Critical Care, Shri Ram Murti Smarak Institute of Medical Sciences, Bareilly, Uttar Pradesh, India, Phone: +91 9949867929, e-mail: kishansing.dr@gmail.com

How to cite this article: Sulakshana S, Naik BK. Critical Illness Polyneuromyopathy and the Diagnostic Dilemma. Indian J Crit Care Med 2020;24(7):603.

Source of support: Nil

Conflict of interest: None

to 48 hours of admission with low potassium levels are better explained by hypokalemia rather than an early onset variant of critical illness polyneuromyopathy. However, critical illness polyneuropathy cannot be denied in the later phase of illness when the patient had ventilator-associated pneumonia due to prolonged ventilation.

\section{References}

1. Mahashabde M, Chaudhary G, Kanchi G, Rohatgi S, Rao P, Patil R, et al. An unusual case of critical illness polyneuromyopathy. Indian J Crit Care Med 2020;24(2):126-128. DOI: 10.5005/jp-journals-10071-23346.

2. Chandramohan G, Dineshkumar T, Arul R, Seenivasan M, Dhanapriya J, Sakthirajan R, et al. Spectrum of hypokalemic paralysis from a tertiary care center in India. Indian J Nephrol 2018;28(5):365-369.

3. Rajshekher G, Kumar S, Prabhakar S. Reversible electrophysiological abnormalities in hypokalemic periodic paralysis. Indian Pediatr 2008;45(1):54-55.

4. Kayal AK, Goswami M, Das M, Jain R. Clinical and biochemical spectrum of hypokalemic paralysis in north: East India. Ann Indian Acad Neurol 2013;16(2):211-217. DOI: 10.4103/0972-2327.112469.

5. Shepherd S, Batra A, Lerner DP. Review of critical illness myopathy and neuropathy. Neurohospitalist 2017;7(1):41-48. DOI: $10.1177 / 1941874416663279$.

(-) The Author(s). 2020 Open Access This article is distributed under the terms of the Creative Commons Attribution 4.0 International License (https://creativecommons. org/licenses/by-nc/4.0/), which permits unrestricted use, distribution, and non-commercial reproduction in any medium, provided you give appropriate credit to the original author(s) and the source, provide a link to the Creative Commons license, and indicate if changes were made. The Creative Commons Public Domain Dedication waiver (http://creativecommons.org/publicdomain/zero/1.0/) applies to the data made available in this article, unless otherwise stated. 